\title{
Analytical Approximation of Advertising Impact on Sale of Products Using Differential Equation Model
}

\author{
Brew Lewis $^{1}$, Boahene Boahemaa Martha ${ }^{1}$, Brew Ebella Candy ${ }^{2}$ \\ ${ }^{1}$ Department of Mathematical Sciences, University of Mines and Technology, Tarkwa, Ghana \\ ${ }^{2}$ African Resource Management, Tarkwa, Ghana
}

Email address:

lbrew@umat.edu.gh (B. Lewis), boahenemarth7@gmail.com (B. B. Martha), brewcand8@gmail.com (B. E. Candy)

\section{To cite this article:}

Brew Lewis, Boahene Boahemaa Martha, Brew Ebella Candy. Analytical Approximation of Advertising Impact on Sale of Products Using Differential Equation Model. American Journal of Applied Mathematics. Vol. 8, No. 4, 2020, pp. 171-175. doi: 10.11648/j.ajam.20200804.11

Received: May 5, 2020; Accepted: June 5, 2020; Published: June 17, 2020

\begin{abstract}
Advertisement involves significant amount of money and remain as one of the major issues bothering companies and other investment sectors. Advertising is a marketing strategy directed to the consumers through any media in order to present and promote product, services and any other cause. Sale of products occurs with or without advertisement and may increase or decrease depending on the market situation. The question is, is there a mathematical model that can surely confirm the effects of advertising on sales of products? The aim of this paper is to develop a first order linear differential equation model that seeks to justify the impacts of advertising on the sale of products in Ghanaian market. Two basic variables, the advertisement and sales of product were considered for the model. A system of two differential equations from the two basic variables were developed and converted to first order non-homogeneous linear differential equation. The geometrical method was employed to obtain qualitative information about the solution of the first order non-homogeneous linear differential equation. The MATLAB software package was used to plots the graphs to illustrate the behaviour of the sale of products with respect to the time of advertisement. The findings revealed that differential equation model can be used to justify the advertising impacts on the sale of products.
\end{abstract}

Keywords: Advertisement, Sale of Products, First Order Differential Equations

\section{Introduction}

Though sales of products are influence by some variables such as growth of population, price changes and retail availability, it is believed that about eighty percent of the sales of products are influence by Advertisement. Advertisement has major influence on customers behaviour towards the purchasing of products [6]. Majority of the customers in the world purchasing behaviour are influenced by the numerous advertisements shown on both electronic and print media and Ghana is no exception. For instance, in Ghana, local products have less demand as compared to the other foreign products due to the increasing advertisement of foreign products in the Ghanaian media. Advertisement seems to be a successful tool of communication in the business sector but it involves huge investments of money. It is a capital investment with no certainty about the duration of benefits. The returns of advertisement, in this case, the sales revenue is not generated immediately in a lump sum, rather it trickles in pieces over time. Though advertisement produces good revenue returns, its major problem bothers on the quality and brand of the products. Consumers are quality conscious and are also associated with the brand, therefore, no matter the number of times the advertisement is carried out, the brand and the quality of the products will play meaningful role in the sales of the product. The issue of making good or poor sales of products depends on how well the advertisement is carried out. This indicates that there exists an effect of advertisement on the sales of product. Generally, one can establish the relationship between advertisement and sales of product. However, the alarming rate at which businesses and other investment sectors are advertising their products in the media has made the effect of advertisement on the sales of product so crucial that many researchers have started working in that area. Many of these research works were carried out in different fields of mathematics. For instance, a research conducted in this area using regression analysis techniques concluded that there exists a significant relationship between advertisement and profitability of companies [3]. Another researcher also used 
descriptive statistics method in his work and concluded that advertisement has an impact on sales increase [1]. Furtherance to this, was the thesis, which supported that good advertisement promotes good sales and enabled business to thrive but requires competent personnel and a number of specialists [4]. The idea to consider the analytical approach in this particular study was motivated by the works of [2]. Though their work was not featured on the sale of products and advertisement, they were able show how analytical solutions could be applied in different fields of study. Their research work was carried on the graphs of analytical solutions to fractional differential equations. At the end of their work they were able to establish a reliable technique to handle differential equations of fractional order. Another work conducted by another researcher also approximates analytic solution for seepage flow using fractional derivatives [7]. With the exception of this research work which centered on analytical solutions for different works, all the other research works relied on available data to deduce the effects of advertisement on the sales of product [7]. The major question is, is there any model that can surely analyze how the advertisement really impact on the sale of products? This is the major focus of this paper. The paper focuses on analyzing the effect of advertisement on the sales of product using mathematical model. No statistical data was used in this research and the result showed that advertisement has effects on the sale of products. Surprisingly, not a single day passes in Ghana without any advertisement shown on the television programs. Advertisement has become so much that it is now one of the prominent programs in all the media in Ghana. The high preference of foreign products by Ghanaians to local products has become too much as a result of the increasing advertisement of foreign products. Directly or indirectly advertisement has become part of the modern businesses and therefore one cannot deal away with it. Indeed, it is one of the prudent ways employed by companies and other investment sectors to generate enough sales from their products. It doesn't matter the approach one choses to organize advertisement to increase sales, there is the need to put in place well developed strategy to win consumers admiration or purchasing behaviour. Because, the survival of companies, investment sectors and other businesses depend on the sales of its products. Indeed, the operating costs and all other responsibilities of the institutions are based on the outcome of the sales of the products. Therefore, it behoves on the companies and other businesses to devise a strategy to condition the mind of the consumers to purchase more of their products. Though the buying behavior of the consumer is influenced by some factors like the brand image, income, life style, culture and so on, the advertisement helps consumers to change their behavior towards certain products. Advertisement provides good strategy to influence consumers mind and has proven to be a successful tool for communication. It also serves as means of communication through media to consumers. Consumers' acceptance of products from the advertisement is very high, since advertisement continues to remind the consumers to use the products. Indeed. the acceptance of the product by the consumer from the advertisement influences his or her purchase many times and thereby affects his or her franchise very rapidly. The advertisement involves all activities in presenting a non-personal and paid for message about a product to audience [5]. The fact is, advertisement is a well thought strategy for marketing products, however, its longterm effects is difficult to predict since it is a strategy that induces other companies to react. Business sectors and other organisations focus on advertising their products when they are not making enough sales and continue to witness high operating costs. Advertisement is a capital investment and has a potential influence of consumers' behaviour on the products. Indeed, it has been defined in many ways in different fields. In one of the research works it was defined as all activities that involve in presenting to group, both personal and non-personal, oral or visual messages regarding a product, service or idea [10]. Advertisement had and continues to play a meaningful role in the survival of business cycles as confirmed by other research works [1]. The benefits of advertisement are enormous that is why companies and other business organizations are investing more funds in that area. The role of advertisement in creating brand loyalty and consequently increasing sales revenue and profits of the organization which had great impact on the business cycle was confirmed by [1] His research concluded on how various sectors were able run effectively by covering their operating cost through enough profits or revenues generated from the sale of products. A research conducted by another researcher also revealed that customers are attracted towards advertisements on media and tend to buy the products they saw in advertisements [9]. Therefore, more companies are concentrating on advertisements strategy to attract more customers to buy their products [8]. Off course the advertisement provides proper market strategy of communicating to consumers, the issue of consumer's behaviour towards the product is also very vital. In the research works of some researchers it was observed that both the advertisement and consumer's behaviour toward the product play crucial role in the sale of products [1], [10] and [8]. Enough strides had been made by these researchers on the study of the effects of advertisement on sales of products in the field of statistics of which the results had been published in several journals. This research is also interested in using models to study the effects of advertisement on the sale of product and so formulates a non-homogeneous first order linear differential equation model to justify these effects. Since the non-homogeneous first order linear differential equation model developed in this research cannot be solved directly, a new approach which leads to a qualitative understanding of the behaviour of solutions is employed. This is done without actually solving the equations. Indeed, in analyzing the geometric solution of the equation, several different cases were considered, depending on the nature of the solution. In each case the behaviour of the trajectories of the solutions of the equations were discussed and illustrated with graphs to provide basic building blocks of the qualitative theory of differential equation. The two basic variables associated with the models with time $t$ include: the sales of the product $S(t)$, and the level of advertisement of the product $A(t)$. These basic variables were assumed to be related by two first order coupled differential equations. The two first order coupled differential equations were merged to form the non-homogeneous first 
order linear differential equation which virtually relates the advertisement of the product $A(t)$ to the sales of the product $S(t)$.

\section{Formulation of Model That Relates Advertisement and Sale of Products}

Suppose the two basic variables, sales of product and advertisement of product are denoted by $S(t)$ and $A(t)$ respectively with respect to time $t$. In constructing the model of the relation between the basic variables, the following assumptions were considered in the general business environment.

i. in the absence of advertisement, thus

$A=A(t)=0$ the rate of sales tends to decrease

$$
\frac{d S}{d t}=-\lambda S
$$

Where $S$ is the sales rate, $t$ is the time and $\lambda$ is constant.

ii. in the presence of advertisement $A=A(t) \neq 0$, we assume that the increase in sales rate is proportional to the advertisement rate and the degree of unsaturation of the market, thus, $\frac{K-S}{K}$ where is $K$ the saturation level of the product. A situation in which the customers who want the products already have them.

iii. As a consequence of these assumptions, we are led to the first order differential equation

$$
\frac{d S}{d t}=\theta A\left(\frac{K-S}{K}\right)-\lambda S
$$

Where $\theta$ and $\lambda$ are positive constants and $K$ is the saturation level of the product. Though this is a linear differential equation with expected solution, the paper only seeks to use this model to justify the effects of advertisement on sales. From equation (1), we have

$$
\frac{d S}{d t}+\left(\frac{\theta A}{K}+\lambda\right) S=\theta A
$$

which depends on the advertisement $A$. In solving Equation (2)

$$
\text { Let }\left(\frac{\theta A}{K}+\lambda\right)=\alpha
$$

Such that Equation (2) takes the form

$$
\frac{d S}{d t}+\alpha S=\theta A
$$

Using the concept of integrating factor, we have the solution of Equation (3) at time $t$ as:

$$
S(t)=\frac{\theta A}{\alpha}+e^{-\alpha(t)} C
$$

The constant $C$ is determined by setting $t=0$ so that we have

$$
C=S(0)-\frac{\theta A}{\alpha}
$$

This implies that

$$
S(t)=\frac{\theta A}{\alpha}+\left(S(0)-\frac{\theta A}{\alpha}\right) e^{-\alpha(t)}
$$

Equation (4) is the sales solution of Equation (1) that depends on the advertisement at time $t$ from $0 \leq t<T$. The final time of advertisement occurs at $t<T$. However, at $t \geq T$ no advertisement was made, thus $A=A(t)=0$, so that from assumption (i) we have:

$$
\frac{d S}{d t}=-\lambda S
$$

therefore, the solution of Equation (5) is given as:

$$
S(t)=C e^{-\lambda t}
$$

At $t=T$ where no advertisement is made $S(t)=S(T)$, hence we have

$$
C=\frac{S(T)}{e^{-\lambda T}}
$$

Therefore, the sales solution of Equation (5) that does not depend on the advertisement at time $t$ or for $t \geq T$ is:

$$
S(t)=S(T) e^{-\lambda(t-T)}
$$

The two analytical solutions provided by Equation (4) and Equation (7) represent the sales that depend on the advertisement and the sales that do not depend on advertisement respectively. From Equation (1) the solution of the differential equation that depends on advertisement is provided by Equation (4). Therefore

Substituting into Equation (4) $\alpha=\left(\frac{\theta A}{K}+\lambda\right)$

We have

$$
S(t)=\frac{\theta A}{\left(\frac{\theta A}{K}+\lambda\right)}+S(0) \frac{\theta A}{\left(\frac{\theta A}{K}+\lambda\right)} e^{-\left(\frac{\theta A}{K}+\lambda\right)(t)}
$$

This implies that 


$$
S(t)=S(0) e^{-\left(\frac{\theta A}{K}+\lambda\right)(t)}+\frac{\theta A}{\left(\frac{\theta A}{K}+\lambda\right)}\left(1-e^{-\left(\frac{\theta A}{K}+\lambda\right)(t)}\right)
$$

is the general sales solution of the differential equation which depends on the advertisement. Also, from Equation (5) the solution of the differential equation that does not depends on advertisement is:

$$
S(t)=S(T) e^{-\lambda(t-T)}
$$

The analytical solutions to the differential equations in Equation (3) and (5) shown in Equation (10) provide the general model of sales with and without advertisement.

Therefore, the piece-wise analytical solution in Equation (10) is developed as the general model to analyse the effect of advertisements on sales.

$$
\begin{gathered}
S(t)=S(0) e^{-\left(\frac{\theta A}{K}+\lambda\right)(t)}+\frac{\theta A}{\left(\frac{\theta A}{K}+\lambda\right)}\left(1-e^{-\left(\frac{\theta A}{K}+\lambda\right)(t)}\right) A=A(t) \neq 0,0 \leq t<T \\
S(T) e^{-\lambda(t-T)} A=0, t \geq T
\end{gathered}
$$

\section{Analytical Approximation of the Model}

The model was stimulated with the advertising campaign data of sale of products and different values of parameters to observe the behaviour of the graphs. Two graphs identified were the sales with advertisement and sales without advertisement. For illustrative purposes, the analytical approximations of the graphs of Equation (10) are shown in Figures 1 to 6 . Figures 1 to 6 shows the approximate solutions of Equation (10) for the values of the parameters $K$, $\lambda$ and $\theta$. In all cases, the corresponding values of $t=0,0.5$, $1.0,1.5 \ldots 6.0$. with different values of $K, \lambda$ and $\theta$ in Figures 1 to 3 and Figures 4 to 6 respectively. The value of the parameter $\lambda$, representing the level of reduction of sales was varied from 0.5 to 0.7 .

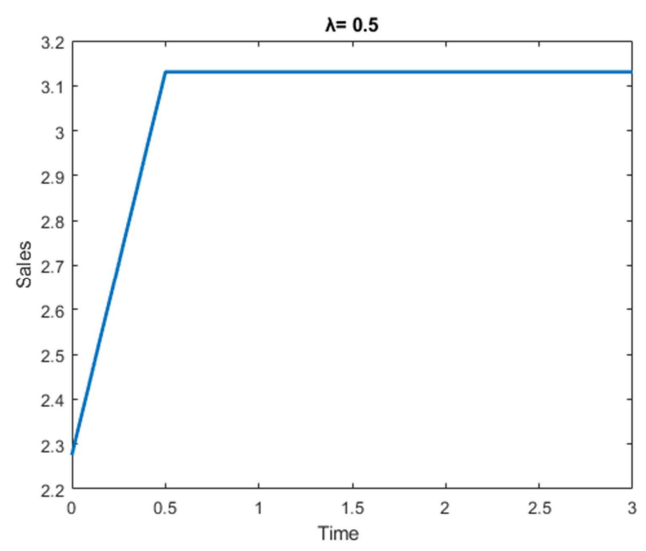

Figure 1. Sale of Product with Advertisement with $\lambda=0.5$.

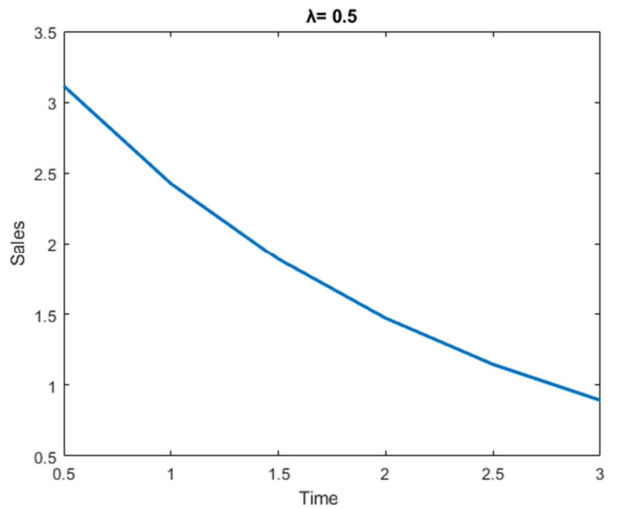

Figure 2. Sale of Product without Advertisement with $\lambda=0.5$.

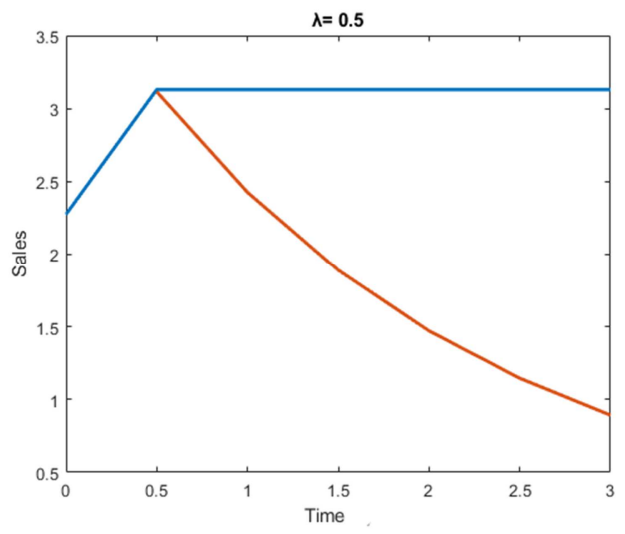

Figure 3. Sale of Products with and without Advertisement with $\lambda=0.5$.

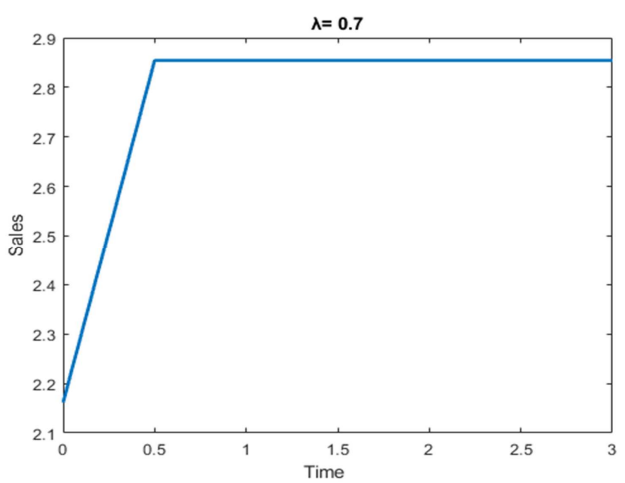

Figure 4. Sale of Product with Advertisement with $\lambda=0.7$.

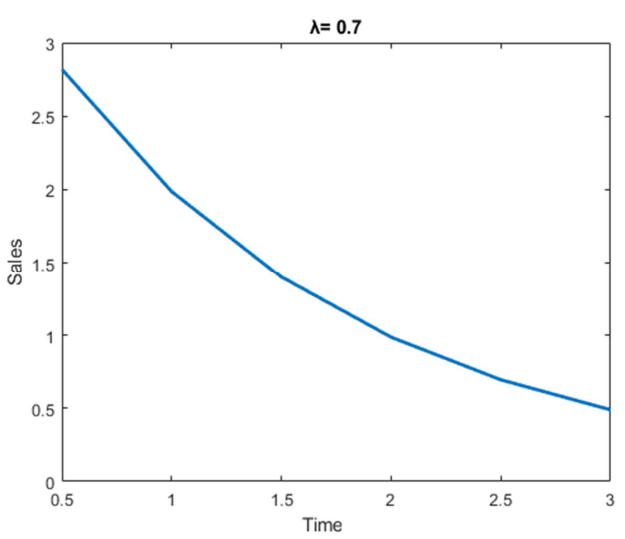

Figure 5. Sale of Product without Advertisement with $\lambda=0.7$. 


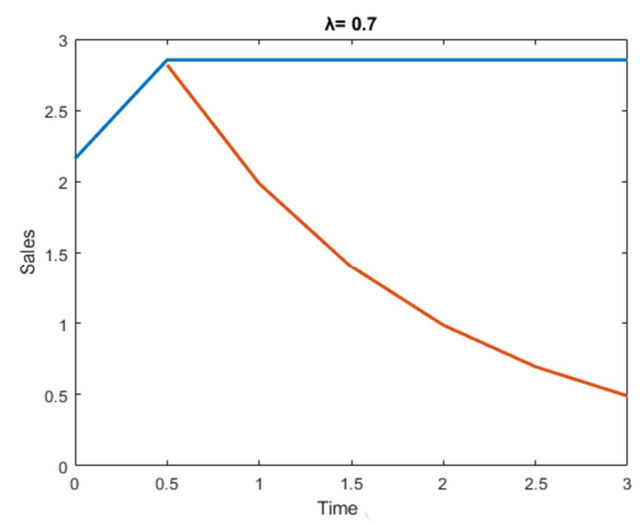

Figure 6. Sale of Products with and without Advertisement with $\lambda=0.7$

\section{Discussions}

Figure 1 presents the sale of products with advertisement. The initial value of sale of products at $t=0$ is $S(0)=2.3$. It was observed that as advertisement increased, sale of products also increased. The rate of sale of products initially, was rapid but remained constant at the saturation level, thus, $\mathrm{K}=3.2$ at time $t=T=0.5$. Figure 2 shows that the sale of products decreased exponentially when the sale of product was carried out without advertisement. Thus, when the advertisement was stopped after time $t=T=0.5$. Figure 3 presents the sale of products with and without advertisement. It was observed in Figure 3 that the sale of products increased initially to the level of saturation $(\mathrm{K}=3.2)$ and started decreasing after that limit and after $\mathrm{t}=0.5$ the sale of the products started decreasing exponentially. In all of these cases, in Figures 1 to 3, Equation (10) was considered for the level of reduction of sales at $\lambda=0.5$. The value of the parameter $\lambda$ was adjusted to 0.7 and the results shown in Figures 4,5 and 6 exhibited the same characteristics but with lower saturation level. Figures 1, 2, 3 and Figures 4, 5, 6 showed that as the value of the $\lambda$ increases, the level of saturation of sale of products decreases.

\section{Conclusion}

Sale of products takes place with or without advertisement. The paper used differential equation model to only justify the effect of advertisement on sale of products in the business environment. The approach was based on analytical solution of the differential equation with various values of the parameters $\lambda, K$ and $\theta$ over a period of time. From the analytical solution of the model it was clear that the sale of products increases rapidly during the initial advertisement. But as it draws closer to the saturation level, it receives small reduction. This was demonstrated in Figures 1, 3, 4 and 6. In all cases, when the advertisement was stopped at a particular time, the sale of products started decaying exponentially as demonstrated in Figures 2, 3, 5 and 6. Figures 2, 3, 5 and 6 showed the exponential decay of the sale of products when the advertisement was stopped at $t=T=0.5$. To ensure sustainable growth in the sale of products and higher revenues, it would be appropriate to continue with advertisement. The paper therefore provided mathematical evidence to support the claim that advertisement has greater effects on the sale of products in the business environment. It further showed with graphs how well the model performed in analysing the impacts of advertisement on sale of products.

\section{Declaration of Conflicting Interests}

We the authors from the above-mentioned institutions, Ghana declare no potential conflicts of interest with respect to the research, authorship, and publication of this paper.

\section{Funding}

We also declare that we did not receive any financial support from any place for the research, authorship, and publication of this paper. Respectfully, we will therefore be happy if our research paper will be published in your highly esteemed journal at a reduced charge or if possible free of charge.

\section{References}

[1] Ashkan, Y. (2016) "The Role of Advertisement in Sales Increase and Promotion: A Case Study of Hamadan Province Insurance Companies", International Journal of Innovative Research in Science, Engineering and Technology, Vol. 5, Issue 4, pp. $6319-6326$

[2] Ahmad, E., Zaid, O., Shaher, M., and Ahmad A., (2010) "Construction of Analytical Solutions to Fractional Differential Equations Using Homotopy Analysis Method", International Journal of Applied Mathematics, Vol. 40, Issue 2.

[3] Agbeja, Adelakun, O. J., Daramola, A. (2019), "Analysis of the Effect of Advertising on Sales and Profitability of Company" International Journal of Novel Research in Marketing Management and Economics, Vol. 2, No. 3, pp: 81-90.

[4] Adekoya, O. A. (2011) "The impact of Advertising on Sales Volume of Product," Bachelor Thesis, HAMK University of Applied Sciences, Finland, pp. 1-38.

[5] Etzel, M. J., Walker, B. J. and Stanton, W. J. (1997) Marketing USA; Irwin/Mc-Graw Hill.

[6] Fill, C. (1999) Marketing Communications: Contexts, Contents, and Strategies. Practice Hall Europe, London.

[7] He, J. H. (1998) "Approximate analytic solution for seepage flow with fractional derivatives in porous media", Comput, Methods Appl. Mech. Eng., Vol. 167, pp. 57-68.

[8] Nidhi Kotwal, N. G. (2008). "Impact of T. V Advertisements on Buying Pattern of Adolescent Girls" Kamla-Raj, J. Soc. Sci., Vol. 16 Issue 1, pp. 51-55

[9] Samar, F., and Samreen, L. (2015) "Impact of Advertisement on Buying Behaviours of the consumers: Study of Cosmetic Industry in Karachi City", International Journal of Management Sciences and Business Research, Vol. 4, Issue 10, pp. 125-137.

[10] Williams, J. S. (1994) Fundamentals of Marketing, Singapore: Mc-Graw - Hill Inc. pp. 67-519. 